\title{
Perceived Occupational Stress and Its Dimensions as Predictors of Organizational Change: A Psychological Study of Doctors Working in DMCH, North Bihar, India during COVID - 19 Outbreaks
}

Dr. Sushama Bharti, PhD*, Prof. (Dr.) Anis Ahmad

University Department of Psychology, L. N. Mithila University, Darbhanga - 846004 India

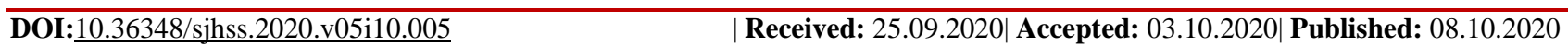

*Corresponding author: Dr. Sushama Bharti, $\mathrm{PhD}$

Abstract

Change is inevitable. If any change occurs during any event whether it's natural or man - made causes stress unless the change is accompanied by some benefits. In the present periods of COVID - 19 outbreaks various changes have been brought into the organizations in particular and among the people in general as per the norms of World Health Organization (WHO). Hence, the present piece of research endeavor is an effort to find out the predictors of organizational change with particular reference to doctors working in Darbhanga Medical College and Hospital (DMCH). For the present study total sample only sixty $(\mathrm{N}=60)$ doctors were selected randomly from Darbhanga Medical College and Hospital (DMCH) by contacting on mobile, WhatsApp and Google mail. Total Subjects' age ranged between 28 to 52 years. Data were collected through questionnaire schedules. After collecting the data on the items of the schedules, individual scores were obtained for giving statistical treatment using SPSS (Statistical Package for the Social Sciences) through computer to find out the predictors influencing organizational change during COVID -19 outbreaks. Having analyzed the data only three dimensions of occupational stress, viz., 'role overload', 'responsibility for persons', and 'strenuous working conditions' have been found as the predictors of organizational change, although, doctors group, undertaken for the present study, working in DMCH have been found to have positive reactions towards change. Finally, obtained results have been discussed in detail by highlighting the exigency of situations prevailing throughout the nations of the world.

Keywords: Occupational Stress, Stressors, Organizational Change, COVID - 19 Outbreaks, Doctors, DMCH, North Bihar, India.

Copyright (C) 2020 The Author(s): This is an open-access article distributed under the terms of the Creative Commons Attribution license which permits unrestricted use, distribution, and reproduction in any medium for non-commercial use (NonCommercial, or CC-BY-NC) provided the original author and source are credited.

\section{INTRODUCTION}

The patterns of Job lifestyle has now become more energetic and innovative based on hi-info-tech especially during COVID - 19 outbreaks. Therefore, management always looks in to the aspect of organizational change for promoting organizations and making organization healthy and productive during COVID - 19 outbreaks. Hence, the present investigation was aimed at studying occupational stress and its stressors towards organizational change with particular reference Doctors working in Darbhanga Medical College and Hospital (DMCH), North Bihar, India.

It is evident from the history that the scenario of the world of work in pre-industrial revolution era was quite different from the present most technologically advanced age. Hence, industrialization, slowly and gradually transformed the simple organizational units and the social systems in to more and more complex systems.

Expanding and developing trend of productive organizations from small units to large organizational network necessitated for the decentralization of work activities. Decentralization created organizational structure based on levels of authority and work responsibilities but individuals in the organization performing different activities are functionally interrelated. Since, the achievement of an organizational objectives especially in Hospitals largely depends upon the fact that human efforts are properly coordinated and integrated, so the problems of coordination and integration have posed a challenge for the management personnel's to develop such strategies especially during 
COVID - 19 outbreaks that may help to smoothen organizational functions by developing coordination at both vertical (superior-subordinate relationship) and horizontal (relationship between persons of the same hierarchical level) levels. And because of these reasons the study of organizational change during COVID - 19 pandemic has always been desired.

We are well aware that human resource, in fact is a key resource but technological resource cannot be overlooked as technological resource in the postindustrial revolution era has increasingly become a dominant resource for improving and controlling quality as well as meeting the optimum level target of organizational productive efficiency. Thus, during the period of COVID - 19 pandemic modernization of technology has become the most desired and accepted tool for the growth and development of organizations. It is imperative to mention that for the modern organizations technology does not only mean machines and tools to be used for making products but the concept being globalize refers to all means opted for smoothening and enhancing operations and organizational productive efficiency [1].

It is apparently clear from the preceding writings that organizational change is pre-requisite for the growth and development of any organization. Researches as well as observations had persuaded the present investigator to carry out research on organizational change. Therefore, the present endeavor was aimed at studying occupational stress and its stressors towards organizational change with particular reference to Doctors working in Darbhanga Medical College and Hospital (DMCH), North Bihar, India.

\section{Justification of the present study}

Change is the law of nature that cannot be overlooked by everyone. Every moment individual and society; individual and organization needs to have planned change in their structure, technology and/or its people. Thus, the study carried out on organizational change in relation to occupational stress is of immense value. Therefore, from now onward, the discussion will be pertaining to the concepts, namely organizational change, occupational stress and its stressors along with the relevant available researches which will be the basis for highlighting the significance of the present piece of research work.

\section{Organizational change}

One of the few elements of the work environment that is recognized as being constant is "change". At present, nearly all organizations are undergoing the process of change. Some are in a constant state of change while others feel to bring change periodically. The transitory phase of change usually receives a great resistance because organizational workers usually fear of losing their importance, promotion, or authority in view of change in the organization, though, it is not generally true however, organizational change in this modern era has become necessary in the wake of changing technology for ensuring the existence and competitive survival of an organization.

Most definitions of organizational change draw attention to its convergent nature, it may bring restructuring of the organization, change in technology, diversification of organization or its products, etc. if organizations do not incorporate the impact of organizational output in their structure, then very soon they may have to undergo another structural change. Organizational structural change might come into focus in establishing responsibilities, allocating tasks, defining communication and improving control systems. On the basis of past researches Ahmad [1] pointed out that organizational change, today, encompasses all round change in technological, financial, material and in the potential human resources which have been witnessed from the contention of Leavitt [2] who emphasized that organization can be changed by altering its structure, its technology and/or its people.

It is also pertinent to point out that change and human attitudes are closely related because attitude are important when any change is brought into the organization, then how change will affect one's need and satisfaction in the organization [3]. The reaction to change may be exhibited in the following forms:

- Acceptance: If an individual perceives that the change will affect him favorably, he accepts it.

- Resistance: If the individual employee feels that the change will affect him unfavorably, he resists it. Resistance to change becomes more forceful when the person concerned has a feeling that through resistance he may eliminate the change.

- Indifference: Sometimes people fail to realize the impact of change or they feel that they will not be affected by the change, either way they remain indifferent.

- Force acceptance: Sometimes people are forced to accept the change, though they may resist it at initial stages but when change forces overpower resistance forces people have to accept it.

Apart from the above mentioned text, it is also important to point out that feelings are the part of each man's personal make-up and cannot be judged by human attitudes and their reaction to change. Generally people have a tendency to resist changes, so, planned change is brought by every organization because in planned change every one gets ample opportunity to go by with the demands of change to serve the organization.

\section{The nature of change}

Human beings are certainly familiar with change and often prove them quite adaptive to it. As we 
know that the faster pace of change required by the electronic age, of the shift to a service economy, and of the growth of global competition has made the solution of the requirement even more important. When manager use their most logical arguments and persuasive skills to support a change, they frequently discover that employees remain unconvinced of the need for it.

Change is any alteration occurring in the work environment that affects the ways in which employees must act. These changes must be planned or unplanned, catastrophic or evolutionary, positive or negative, strong or weak, slow or rapid, and stimulated either internally or externally [4].Regardless of their source, nature, origin, pace, or strength, changes can have profound effects on their recipients [5].

It is an important to be pointed out that many of the organizational changes that occur on a daily basis are somewhat slight. They may affect only a few people, and they may be incremental in nature and relatively predictable. For example as new procedures evolve or as new members are added to a work group, existing employees generally do not need to change all dimensions of their jobs or acquire totally new behaviors. In such situations a new equilibrium may reach readily.

A wide variety of force, however, may bring about more impressive change that touches the entire core of an organization. Many of these have become much more common as the economy, competition, and pace of technological change may become more volatile for the survival of human being during COVID - 19 outbreaks.

Some changes originate within the organization, but many come from the external environment. Government passes laws, and the organization must comply. New development in technology arises, and products must incorporate the changes and these days competitors introduce new services, and the firm must respond. Then there are pressures from customers, labor unions, communities and other who initiate changes to protect themselves from COVID - 19 pandemic. Although, stable environment means less change, dynamic environment, are now the norm and they require more change. On occasion they can cause difficulties for employees especially in this incident.

Before terminating the complete descriptions of organizational change - as a dependent variable it is necessary to point out some of the observations experienced by present investigators. During the present COVID -19 pandemic it is observed that change is everywhere, and its pace is increasing. The work environment is filled with change that often upsets the social system and requires employees to adjust. When they do, employees respond with their emotions as well as rational reasoning. Change has costs as well as benefits, and both must be considered to determine net effects. Moreover, employees tend to resist change because of its costs, including its psychic costs. Resistance to change can stem from the change process itself, the way it was introduced, or the perception of inequitable impact. It is further seen that it can be logical, psychological, or sociological.

Now the on-going description will be pertaining to occupational stress and its stressors - one of the independent variables.

\section{Occupational stress}

Any change causes stress. Thus, in the present day world especially in the time of COVID - 19 'job life' has become probably the most significant aspect of one's life because people keep themselves engaged in some job where they spend more time than in any activity but sleeping. Those who are working in any industry or organization may develop apprehensions and vague as a result of various unpleasant stressful and threatening work situations. Therefore, the phenomenon of stress, in general, and job stress in particular, is more important to be studied, especially, in the work situation to identify stressors. It is because of the fact that resistance to change may be the cause of stressors.

The term 'stress' emanating from Latin literature, it was first used in English during $17^{\text {th }}$ century and the term means distress, oppressions, and hardships. During the $18^{\text {th }}$ and $19^{\text {th }}$ century the meaning of stress shifted to natural sciences and engineering to represent force, pressure or strain, and or strong influence acting on a physical object or person which an individual resists in an attempt to maintain his original state.

Bridgewater and Sherwood [6] have indicated in the Columbia Encyclopedia, stress is the internal force exerted by one part of a body upon the adjoining part, while strain is the deformation or change in dimension occasioned by stress. When body is subjected to pull it is said to be under tension, and when it is being pushed, i.e., is supporting a weight, it is under compressive stress. Sharing stress results from a force tending to make part of the body or one side of a plane slide past the other. Tensional stress occurs when external forces tend to twist a body around an axis. Thus, Stress has become a part of life. Nowadays, everyone seems to be talking about stress. We also hear it not only in daily conversation but also through television, radio, the newspapers, conferences, stress centers, and university courses devoted to the topic. Remarkably, few people define the concept the same way and hardly bother to attempt for a clear-cut definition. In general, stress occurs when biological and physiological needs, as well as external demands and pressures are greater than the ability of the individual to adapt. According to Basowitz et al. [7] stressful 
situations do not always produce responses in individuals. In the light of this view Panchanathan and Shanmugaganesan [8] have inferred that stress is a reaction to something that is happening to an individual. Moreover, it is one's way of coping with environment and threatening situations that he faces daily [9].

Selye [10] in his pioneering work used the concept of stress in a manner relevant in social sciences. Selye expounded his biological concept of stress as the "General Adaptation Syndrome" (GAS):- a three phase response to stress that begins with an alarm, continues with resistance, and terminates with exhaustion. This three phase response to stress incorporates the orchestrated set of physical and chemical changes which prepare an individual to fight or flee. The present day world abounds with uncertainties, which include natural calamities as well as unpredictable events and incidents [11].

It has been, in all times, a universal truth that the world is changing which is very much evident in the present era. Thus, the change and its effects have become the dominant features as the various authors have written on the Age of discontinuity [12], the Age of Uncertainty [13] and the Age of Anxiety [14]. However, the change is a continuous process which in itself is a great stressor in human life. In view of Lazarus [15] stress is a universal human and animal phenomenon. A review of definition on stress reveals that stress has been one of the important aspects that everyone has experienced but few could define, Lazarus [15] stated that stress results in intense and distressing experience that appears to have tremendous influence on behavior.

Apart from the above context, it is to be mentioned here that stress is the general term applied to the pressures people feel in life. The presence of stress at work is almost inevitable in many jobs. However, individual differences account for a wide range of reactions to stress; a task viewed as challenging by one person may produce high level of anxiety in another. When a pressure begins to build up, it can cause adverse strain on a person's emotions, thought processes, and physical condition. When stress becomes excessive employees develop various symptoms of stress that can harm their job performance and health and even threaten their ability to cope with the environment. The people who are stressed may become nervous and chronically worried. They are early provoked to anger and are unable to relax. They may be uncooperative or use alcohol or other drugs excessively. Although these conditions also occur from other causes, they are common symptoms of underlying stress.

\section{Stressors}

Apart from the stressors outside the organization there are also stressors those are associated with the organization itself. Changes in working practices, such as the introduction of new technology or the alterations of targets, may cause stress, or stress may be in built in to an organization's structure. In an important study Cooper et al. [16] model identified five important sources of work stress. They are as follows:

- The job itself: This includes the working environment, hours worked including shift work, travel, work load and keeping up with new technology.

- Role in the organization: This covers role conflict, ambiguity of role, lack of clarity in particular and responsibility for other people as part of the job role.

- Relationships at work: One of the most stressful aspects of work is building and sustaining positive and supportive relationships with colleagues, bosses and subordinates.

- Career development: This includes job insecurity redundancy, skill obsolescence, reaching one's career ceiling or being over-promoted.

- Organization structure and climate: This impacts on the extent to which individuals feel to participate in decisions affecting them.

The source of external job stress is more a 'catch-all' for all those interfaces between life outside and life inside the organization that might put pressures on the managers; family problems [17], life crises [18, 19], financial difficulties, conflict of personal beliefs with those of the company and the conflict of company with family demands. It is generally recognized that a person's family has a big impact on personality development. Even research indicating that in dual career families, stressed out husband may transient his stress to his life. Some stress researchers define their personal life stressors as unresolved environmental demands, requiring adaptive behavior in the team of social adjustment [20-22]. Apart from the family, societal/ technologies change, relocation, race/class and residential/community conditions also affects substantially [23]. A number of working women were reported feeling personal or family stress which in turn leads to job stress [24], although one researcher identified that the condition of housing, convenience of service \& shopping, neighborhood/neighbourtness degree of noise and air pollution are likely to be stressors [25].

\section{CONSEQUENCES OF STRESS}

Ever since the hoary past, one of the important goals of mankind has been in pursuit of happiness, peace and stress free life. The process has led us from stage to stage till we find ourselves caught in a dynamic technological whirlpool which has spared mega bureaucracies, micro task specialization and greater urbanization. Phenomenon like there are closely linked with work settings which have numerous systems such as production, finance, marketing, administration as well as macro organizational sub-systems like interorganizational system \& organizational level goals, 
strategies, climates, cultures, structures, management styles and performance. There are accountable for the growth of the organization \& its role incumbents on the one hand and society at large, on the other very often the human in the system is reduced to a more insignificant spoke in the wheel of the total technological set-up. This trends to generate feelings of powerlessness, meaninglessness, and normlessness and consequently stress. At times stress is not automatically bad for individual employees/their organizational performances. In fact it is generally observed that low level of stress can even change job performance. In one of the important studies found that mild stress, such as getting a new supervisor/being involuntarily transferred may have the result of an increased search for information in the job [26]. Emerging research also indicates that the level of difficulty, the nature of the task being performed personal and psychological disposition may effects the relation between stress and performance [27]. However, emerging researches have indicated that the performance in many tasks is in fact strongly affected by stress and performance usually drops of sharply when stress rises to high levels [28].

Similarly, a lot of work on occupational stress has been carried out so far, and number of stressors or determinants of stress at work have been identified. Parker and De Cottis [29] have identified three sets of factors-environmental, organizational, and individual. These factors act as potential sources of stress. Holmes and Rahe [30] have given a list of more than 40 life change events that create stress for individuals. They also contended that accumulation of life change events lowers the bodies resistance capabilities and enhances the probability of increasing stress, illness and health problem there life change events are all individual factors which for example, include death of spouse, divorce, detention in jail or other institution, major personal injury or illness, being fired at work, sexual difficulties, major change in financial state, trouble with boss, major change in working hours or conditions, change in residence, changing to a different time of work, etc. from the nature of the listed life events, it is amply clear that almost all the events are related to the individual factors as have been given by Parker and De Cottis [29]. Certain dimensions/stressors of occupational stress and some biographical variables as the predictors of organizational change which would be having their greatest implications for the organizations especially, where from the samples of this study were drawn and also for other similar organizations throughout the nations of the world in general, although, few studies on organizational change in relation to different dimensions of organizational psychology have been studied by (Ahmad, 1995, 1999, 2000, 2001, 2003). Recently, [31] studied job stress during COVID - 19 pandemic among teaching and non - teaching employees and they found significant difference between the groups of teaching and non teaching employees in terms of their perceived job stress during the COVID - 19 pandemic. Moreover, various dimensions of occupational stress viz., role overload, role ambiguity, role conflict, unreasonable group and political pressure, responsibility for persons, under participation and strenuous working conditions have been emerged as the predictors of occupational stress between the group of teaching and non - teaching employees during COVID - 19 pandemic.

To conclude the preceding writings, it is an important to point out that, in our own nation - India, the pace of organizational development is very slow and poor largely because of the fact that researchers have almost neglected the study on organizational change which could have given appropriate information about the relevant areas of change conducive for organizational development especially during the COVID - 19. Thus, the present endeavor is a stride in this direction which will fill the void of knowledge by disseminating information regarding the predictors of organizational change.

\section{SIGNIFICANCE OF THE PRESENT STUDY}

Having looked upon the available literature on organizational change and occupational stress, it has been observed that organizational change studies, being negligible in number especially in Indian context, requires much more attention as this is necessary for organizational growth and development and, in turn, the growth of the national income as well.

In our own nation - India, hospital organization play an important role in the nation's well - being but due to economic uncertainty during COVID - 19 pandemic they have brought some changes for its smooth running and continuously engaged in contributing their services for the healthy nation's building developments, process and communication. Therefore, the present research becomes a significant one from this point of view that it will give the recent idea in the area of interdisciplinary approach. Moreover, findings of the present study will highlight the present situation and would help in making policies for the promotion of hospital organization in Northern India, in particular and similar organizations in worldwide in general. It is important to mention here that the study was still an unexplored area so, the present study is of immense value and it will fill the void of knowledge in the area concerned. By looking at facts, the present study was aimed at studying the job stress towards organizational change with particular reference to doctors working in Darbhanga Medical College and Hospital (DMCH) of North Bihar, India.

\section{OBJECTIVES OF THE PRESENT STUDY}

Organizational change is witnessed from the fast changing scenario of the world of work so; it is always desirable as a result of change in policies, technology and other organizational modernization and advancement to cope with the demands in a particular 
time frame especially during the period of COVID - 19 outbreaks. It is very interesting to point out here that hospital organization especially in India also going along with the desired change in technology, organizational structure and human resources are the most successful organizations having the quest of increasing a higher number of good organizational productive efficiency. Hence, objectives of the present research is amply clear as it endeavors to see the effect of Job stress and its stressors on doctors' perceived reactions towards organizational change. The present study will fill the void of knowledge in the area concerned and in other allied areas and the findings may suggest proper directions for developing healthy work environment and culture within the hospital organization in particular and in other similar organizations in general. Hence, the present study is of utmost value especially for the promotion of healthy hospital organization throughout the glob.

\section{HYPOTHESES}

On the basis of the broad objectives of the present study, it has been observed that no studies have been reported the relationship of job stress and its stressors (Independent Variables) towards organizational change (Dependant Variable) with particular reference to doctor employees of India with particular reference to Darbhanga Medical College and Hospital (DMCH). Therefore, it has been decided to adopt null hypothesis. So, the following hypotheses have been formulated.

- It has been presumed that none of the independent variables (Job Stress and its stressors) will predict Doctors' Perceived reactions towards organizational change (Dependent variable) during COVID - 19

- Moreover, none of the biographical variables as stressors will predict the Doctors' perceived reactions towards organizational change.

\section{METHODOLOGY \\ Sample:}

In the present study, the total sample consisted of sixty one doctors $(\mathrm{N}=61)$ employees who have been randomly selected from the various departments of Darbhanga Medical College and Hospital (DMCH) of North Bihar, India. Near about 75 schedules had been filled in by the doctors of DMCH but having scrutinized the schedules only 61 schedules were selected for tabulating the data. Total subjects' age were ranged between 28 to 52 years.

\section{Tools Used}

The following tools were used for the present piece of research work.

1. Organizational Change Scale: For the measurement of Textiles Industries employees' perceived reactions towards organizational change, a scale developed by Rahman and Akhtar [32] was used. The scale consisted of 25 items and all the items are positively phrased except the one, i.e., item No.6. The subjects were required to give responses to the items on a 5-point scale ranging from "Strongly Agree" to "Strongly Disagree". The reported split-half reliability of the scale is $r=.85$ which confirms the reliability of organizational change scale.

2. Occupational Stress Index: Using this scale, level of Job/Occupational stress, as well as, the areas of occupational index has been developed by Srivastava and Singh [33] which consisted of 46 items covering 12 dimensions of occupational stress. These dimensions have been stated by the authors as sub-scales (or Job/Occupational stressors) are - (1) role overload, (2) role ambiguity, (3) role conflict, (4) unreasonable group and political pressures, (5) responsibility for persons, (6) under participation, (7) powerlessness, (8) poor peer-relations, (9) intrinsic impoverishment, (10) low status, (11) strenuous working conditions, and (12) un profitability . Covering 12 - sub-dimensions as job stressors, in all, which had to be rated on a 5-point scale "ranging from" strongly agree to strongly disagree. Out of 46 items, 28 are true-keyed items and the remaining 18 items are false-keyed items. The reported split-half reliability of the scale is .94 ; hence, it confirms the efficacy of the scale. The brief description of the stressors of job stress used by the present investigator in the context of present study is stated below:

- Role Overload: A state in which the work responsibility given to a person needs more time and resources than is available to him.

- Role Ambiguity: A state in which the person has inadequate information to perform his role (information about work objectives, scope and responsibility of the job, expectation of significant others and scope of jurisdiction and authorities.

- Role Conflict: A situation where the demands made on a person are contradictory or are in conflict with his own expectations and working style.

- Unreasonable Group and Political Pressure: A situation in which one is required to take a lot of decisions against his will or against formal rules and procedures under pressure.

- Responsibility for Persons: A person has the responsibility for the work, productivity and development of many employees.

- Under participation : Lack of one's influence on decision making process of the organization

- Powerlessness: A situation in which authority given does not commensurate with the responsibilities of the Job.

- Poor Peer-Relations : A situation in which relationships coworkers are characterized by low trust, low supportiveness and low interest in listening to and trying to deal with the problems confronting the other .

- Intrinsic Impoverishment: Lack of opportunity to realize one's potential abilities and develop one's aptitude. 
- Low Status: A state of insignificance in the organizational network as well as in the social system.

- Strenuous Working Conditions: Lack of comfort and safety on the job.

- Unprofitability: Poor compensation and reward for the work done.

\section{BIOGRAPHICAL INFORMATION BLANK} (BIB): For taping information regarding the respondents biographies, a "Biographical Information Blank" (BIB) was also prepared that included age, marital status, salary (basic and gross), qualification designation , department, total experience (in years), present experience (in years) and number of dependents and the respondents were requested to furnish these information.

\section{Procedures}

The above three test materials viz., organizational change scale, occupational stress index and, biographical information blank were in printed form and were administered individually on all the doctors during COVID - 19 unlock - IV by maintaining social distancing and taking other precautions as per the guideline of India. During data collection all doctors working in Darbhanga Medical College and Hospital were assured by taking in to confidence that provided information will be kept strictly confidential and will be used for research purposes only.

Having collected the responses to the items of the scales, they were scored according to the procedure and the individual scores were obtained. Finally, scores were given statistical treatment to find out the predictors of organizational change and presented in tables. The obtained results were discussed and the formulated hypotheses were tested.

\section{Statistical analyses}

In this study, standard multiple regressions out of various multiple regressions have been used as this analysis through SPSS was made available. This strategy allows all independent variables to get inter simultaneously into the regression equation. Each independent variable is evaluated in terms of what it adds to go prediction on the dependent variable. Apart from regression analysis, Q1 and Q3 were also calculated to obtain the groups, differing in levels of their perceived reactions to organizational change.

\section{RESULTS AND DISCUSSION}

Results: The present study was aimed at investigating the occupational stress and it stressors towards organizational change with particular reference to Textiles Industries employees located in Northern India. It is apparently clear from the research topic that employees perceived reactions towards organizational change (OC) is a dependent variable (DV) which was studied with reference to job stress (OS) and its stressors. In addition to this some biographical variables such as age, total experience, experience in the present positions, salary and number of dependents was also undertaken as the stressors (IVs) in the present study so, job stress and biographical variables had operated as Independent variables (IVs) in this study.

In the present research endeavor two types of analyses for obtaining results were applied. Firstly, Textiles Industries employees perceived reactions towards organizational change were obtained by calculating $\mathrm{Q}_{1}$ and $\mathrm{Q}_{3}$ that created three levels of employees' perceived reactions towards OC, denoting low $\left(\mathrm{Q}_{1}\right.$ and its below values), moderate (between $\mathrm{Q}_{1}$ and $\left.\mathrm{Q}_{3}\right)$, and high $\left(\mathrm{Q}_{3}\right.$ and above values). And under these three categories only percentages of employees have been given for the total sample. Percentage is not usually considered to be a sophisticated statistical techniques but sometimes this technique seems to become necessary that gives a very clear picture of the trend of results, hence, it has been used in this study for inferring the pattern of employees' perceived reactions towards OC.

The another statistics which was applied in this valuable and innovative study was "Standard Multiple Regression Analysis" which is quite a modern statistical technique in which all the independent variables could have been simultaneously entered for studying their influences on a dependent variable. This analysis has been found appropriate for predicting the influence of Independent variables (IVs) on employees' perceived reactions towards organizational change- a dependent variable.

Coming to the description of results, it is important to mention that the findings of this study fall under two broad categories. The first category depicts the levels of employees' perceived reactions towards organizational change, whereas, in the second category of results, the employees' perceived reactions towards organizational change will be predicted as function of job stress and along with certain biographical variables such as age, total experience, experience in the present positions, salary, number of dependents.

Table-1: Showing Extent of Doctors' Perceived Reactions towards Organizational Change (OC) Working $(\mathbf{N}=61)$

\begin{tabular}{|l|l|l|}
\hline Levels & N & Percentage \\
\hline High & 26 & $42.62 \%$ \\
\hline Moderate & 29 & $47.54 \%$ \\
\hline Low & 06 & $9.84 \%$ \\
\hline \multicolumn{3}{|l|}{ Mean value of Organizational Change $=\mathbf{9 7 . 3 0}$} \\
\hline
\end{tabular}

In quest of investigating extent of employees' perceived reactions towards organizational change (OC) of the total sample, it is important to point out at this juncture that the analyses of the total sample group have revealed the fact that employees, in general, have 
shown their favorable attitudes towards the changes brought in the Darbhanga Medical College and Hospital (DMCH) as obtained mean value of organizational change (OC) is 97.30 which already fall at the higher side of acceptability to change because the maximum value which could have been obtained by employees for showing their absolute reactions to the acceptance of change would have been only 125 at the most. Therefore, what levels of perceived reactions towards change in this study are being emphasized all fall only under the category of favorable reactions to change. From the table -1 , it can be observed that 42.62 percent of doctors working in DMCH have very high acceptability reactions towards organizational change, 47.54 percent have moderate perceived acceptability, and 9.84 percent of the doctors have shown their low but favorable acceptability to organizational change. The above mentioned results can also be observed by the following pie chart:

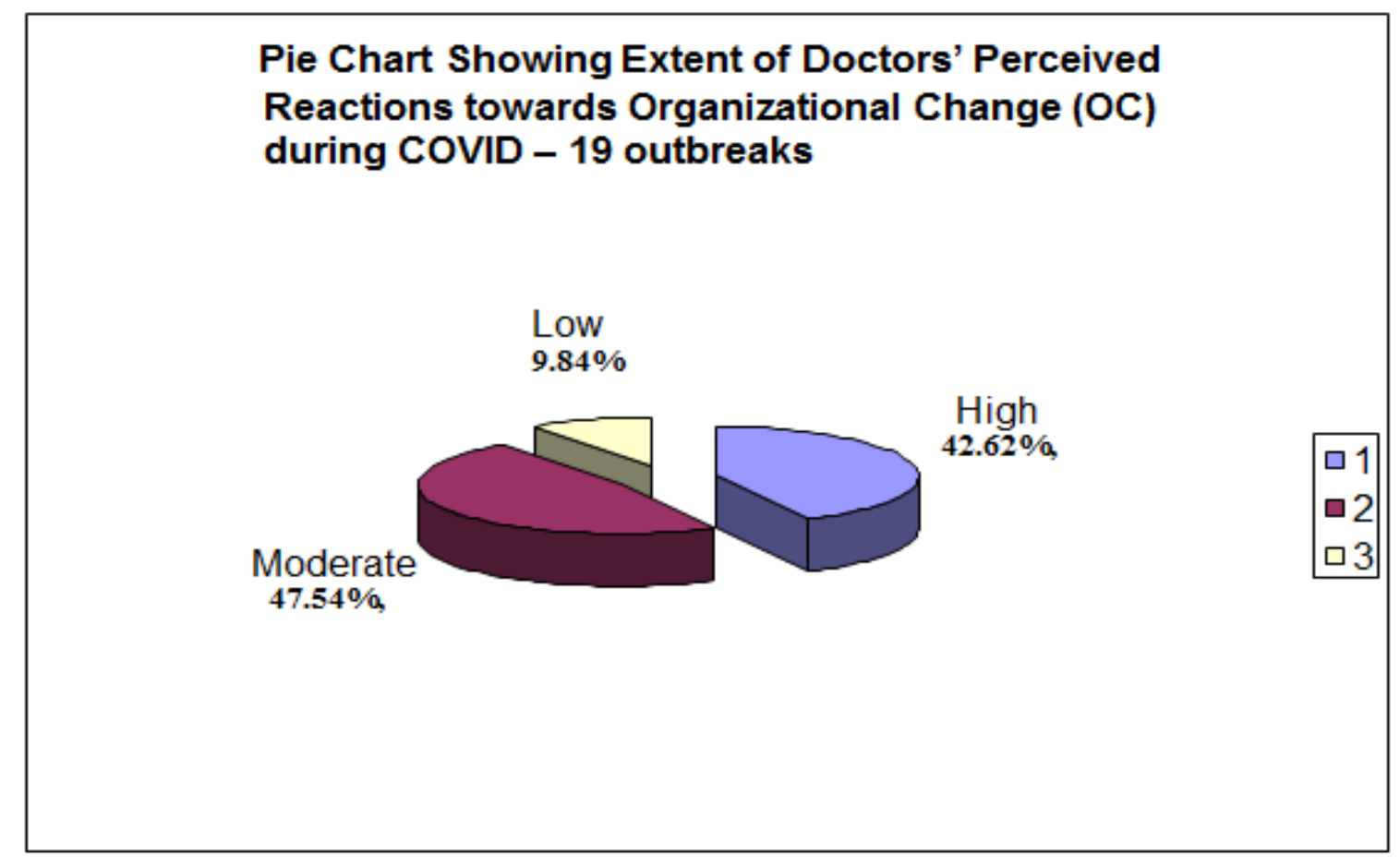

Table- 2: Analysis of Variance for Regression of Doctors Working in DMCH (N = 61)

\begin{tabular}{|c|c|c|c|c|}
\hline Source of variation & df & Sum of squares & Mean squares & F. value \\
\hline Attributable to Regression & 18 & 632.56726 & 34.85437 & \multirow{2}{*}{$2.36243^{* *}$} \\
\hline Deviation from Regression & 42 & 624.38795 & 13.67837 & \\
\hline Total & 60 & & & \\
\hline
\end{tabular}

* Significant at .01 levels: ** Significant at .05 level

The Analysis of Variance for the regression analysis of doctors as shown in table -2 indicates that independent variables, namely, job stress as a whole, as well as its various dimensions or stressors, and the different biographical variables, have been found predicting doctors' perceived reactions towards organizational change as obtained F-value 2.36243 has been found statistically significant at .05 level of confidence. Hence the stated hypotheses that none of the independent variables (IVs) will predict the dependent variable stand rejected. In continuation, Table 3 gives a clear cut picture of the trend of results. Therefore, it is necessary to pin - point the specific predictors influencing doctors' reactions towards organizational change. From the table - 3 it could be observed that dimensions of occupational stress or factors of occupational stress viz., "Role overload", "Responsibility for Persons", and "Strenuous Working Condition", and from biographical characteristics "Age" and "Experience in the Present Position" have been emerged as the real predictors of organizational change from where the present sample has been drawn as their respective t-values-2.93743; 2.10363, 3.12630; $2.91719 ; 2.21035$ and 2.04668 have been found to be significant statistically. 
Table- 3: Multiple Regression Analysis of Doctors Working in DMCH (N = 61)

\begin{tabular}{|l|l|l|l|l|l|}
\hline Sl.No. & Variables & Value of "r" & $\begin{array}{l}\text { Regression } \\
\text { coefficient }\end{array}$ & $\begin{array}{l}\text { Std. Error } \\
\text { regression coefficient }\end{array}$ & t-value \\
\hline 1 & Role overload & -0.20415 & -0.63211 & 1.76382 & $2.83003^{*}$ \\
\hline 2 & Role ambiguity & -0.21165 & -0.75162 & 0.71111 & 1.07106 \\
\hline 3 & Role conflict & -0.02886 & 0.511277 & 0.70431 & 0.63567 \\
\hline 4 & $\begin{array}{l}\text { Unreasonable group and } \\
\text { political pressure }\end{array}$ & -0.11012 & -0.83526 & 0.74815 & 1.23201 \\
\hline 5 & Responsibility for persons & -0.12758 & -0.04733 & 1.74136 & $2.35417 *$ \\
\hline 6 & Under participation & -0.04962 & -0.52804 & 0.48037 & 1.10117 \\
\hline 7 & Powerlessness & 0.0460 & -1.12067 & 0.79033 & 1.42037 \\
\hline 8 & Poor peer-relations & 0.06460 & -1.13057 & 0.79033 & 1.43036 \\
\hline 9 & Intrinsic impoverishment & 0.23143 & 0.33418 & 0.81514 & 0.42213 \\
\hline 10 & Low status & -0.32531 & -1.35752 & 0.92747 & 1.45718 \\
\hline 11 & $\begin{array}{l}\text { Strenuous working } \\
\text { conditions }\end{array}$ & -0.41715 & -1.12437 & 0.83887 & $2.33878^{*}$ \\
\hline 12 & Unprofitability & -0.47337 & -2.37537 & 0.09776 & 1.16075 \\
\hline 13 & Total occupational stress & -0.33406 & 0.52408 & 0.66572 & 0.77585 \\
\hline 14 & Age & -0.11521 & -0.43203 & 0.49603 & 0.86721 \\
\hline 15 & Total experience & -0.09568 & 0.45517 & 0.88315 & 0.46786 \\
\hline 16 & $\begin{array}{l}\text { Experience in the present } \\
\text { position }\end{array}$ & -0.05024 & 0.60011 & 1.15840 & 0.51647 \\
\hline 17 & Salary & & & \\
\hline 18 & Number of dependents & -0.02003 & 0.57655 & 0.95168 & 1.37240 \\
\hline
\end{tabular}

Dependent: Organizational change

$$
\text { Mean: } 97.30842
$$

SD: 4.73324

Intercept: 79.86529

Multiple correlations: 117.54120

Standard Error of Estimate: 3.59642

Note: * Significant of .01 levels

** Significant at .05 level

A bird's eye over the tables from 2 and 3 revealed that all doctors working in Darbhanga Medical College and Hospital (DMCH) of North Bihar, India have shown favorable inclination towards organizational change (O.C.). Moreover, it is also evident from the findings that 3 dimensions/stressors of occupational stress, out of 12 dimensions have been found predicting doctors' perceived reactions towards organizational change. The dimensions which have been resulted for attributing to the doctors' perceived reactions towards organizational change are - "Role overload"; "Responsibility for Persons" and "Strenuous Working Conditions" have also been found as predictors of organizational change.

In the light of the results obtained it is pertinent to point out that doctors' reactions to organizational change can be predicted by the number of factors inherent in the job itself. These factors include 'role overload', 'responsibility for persons'; 'strenuous working conditions', all these are the dimensions of occupational stress. It is important to mention here and it can also be observed from the table - 3 that none of the biographical variables have been found to predicting organizational change especially in the time of COVID - 19 pandemic. The pattern of the result outcomes seems to be logical as resistance to change is most likely to occur in the situation where there is a probability of high job stress as well as lesser or no chance of upward mobility but such conditions do not exist in the present conditions of the work group under discussion. It is evident from the sample data that the doctors working in Darbhanga Medical College and Hospital (DMCH) especially in Northern India have low or moderate level of occupational stress in general, as well as, they have greater chance of upward mobility with respect to either designation or salary structure, therefore, some of the dimensions of occupational stress have been found to have their predictive influence on doctors' perceived reactions towards organizational change.

In addition to the above explanation, it is also important to mention the average age of the sample is only around 40 years, hence, doctors taken in this investigation were quite above average age who would have their aspirations to grow more, to have greater responsibility in the organization during COVID - 19 outbreaks especially where from the sample has been drawn, to get maximum profit out of their inputs, and to earn higher status in their job life. 
In view of these above perceived expectations, doctors working in DMCH have shown their positive acceptability to organizational change as per the guidelines of World Health Organization (WHO). Therefore, it is important for the organizations that they should always develop awareness among their employees in particular and among the people in general about the benefits of patterns of changing lifestyle in the time COVID - 19 outbreaks. Changes undertaken during pandemic will create for them enough ventures to fulfill aspirations in the course of their work life in future too. Our contention is almost similar to the opinions of Mumford [34], Lucas [20], Kruger \& Miller [22], and Jones, et al. [35] who believed that the tendency of employee is usually to dislike change unless the change is accompanied by rewards and compensation.

\section{CONCLUSIONS}

In the light of the results and discussion the following conclusions are drawn:

1. All the doctors working in Darbhanga Medical College and Hospital (DMCH) have been found positive inclination towards organizational change during COVID - 19 outbreaks.

2. Out of twelve dimensions of occupational stress, three dimensions, namely, 'Role Overload', 'Responsibility for Persons', and 'Strenuous Working Conditions' have been found influencing as the predictors of organizational change.

3. On the basis of observation, it is important to mention here that the present era is considered as the era of modernization based on hi-info-tech so that people in general needs positive social feedback in order to enhance their job life career, and to develop a self-image which is the need of hour for maintaining quality of dignity in their life endeavor by providing self - awareness programme pertaining to the evils of COVID - 19 outbreaks which is more serious problem nowadays throughout the world. Finally, it is suggested that a larger and varied cross-cultural sample doctors is needed for further research on the direction opted by the present investigators which will help in making strategies to fight with COVID - 19 pandemic.

4. Finally, it is worth mentioning that Corona virus disease (COVID-19) is an infectious disease caused by a newly discovered. Most people infected with the COVID-19 virus will experience mild to moderate respiratory illness and recover without requiring special treatment. Older people and those with underlying medical problems like cardiovascular disease, diabetes, chronic respiratory disease, and cancer are more likely to develop serious illness. The best way to prevent and slow down transmission is be well informed about the COVID-19 virus, the disease it causes and how it spreads. To protect yourself and others from infection by washing your hands or using an alcohol based rub frequently and not touching your face. It is important to mention that the COVID-19 virus spreads primarily through droplets of saliva or discharge from the nose when an infected person coughs or sneezes (WHO), so it's important that you also practice respiratory etiquette (for example, by coughing into a flexed elbow). At this time, there are no specific vaccines or treatments for COVID-19. Hence we must take care in all respect by maintaining social distance. This is only the solution to be free from all sorts of stress. During this period, it is suggested only organizational change as per the norms of WHO can give us more benefits to fight with the COVID - 19 outbreaks.

\section{ACKNOWLEDGEMENT}

Authors express their indebtedness to $\boldsymbol{D r}$.

Nirmal Kumar Mandal, Department of Community Medicine, Darbhanga Medical College and Hospital, $(\mathrm{DMCH})$ who cooperated more than one way during present research work.

\section{REFERENCES}

1. Anis, A. (1994). Occupational Stress and Certain Biographical Variables as Predicators of Organizational Change.Journal of Community Guidance and Research-An International multidisciplinary Cross-Cultural Journal, 2(2), 95103.

2. Leavitt, H. J. (1965). Applied organizational change in industry, structural, technological and humanistic approaches. Handbook of organizations, 264.

3. Ahmad, A. (2010). Enhancing Business Effectiveness through Organizational Change. Business Psychology. Edited by Novrattan Sharma and Amrita Yadav. Global Vision Publishing House, New Delhi.

4. Duening, T. (1997). Our turbulent times? The case for evolutionary organizational change. Business Horizons, 40(1), 2-9.

5. McKINLAY, A., \& Starkey, K. (1988). Competitive strategies and organizational change. Organization Studies, 9(4), 555-571.

6. Bridgwater, W., \& Sherwood, Elizabeth J. (1956). The Columbia Encyclopedia, second edition, 19041905.

7. Basowitz, (1955). Anxiety and Stress. New York: MacGraw Hill.

8. Panchanathan, M., \& Shanmugaganesan, V. (1992). The effect of Psychological stress on academic achievement. Journal of community guidance and research, 9(2), 139-149.

9. McGrath, J.E. (1976). Stress and Behaviour in Organization. In M. Dunnette (Ed.), Handbook of Industrial and organizational Psychology, Chicago: Rand McNally.

10. Selye, H. (1956). The Stress of life. New York: McGraw Hill.

11. Margetts, E. L. (1975). Stress, Homeostasis, and the Human Ecological Continuum in Time: Some 
Implications for Psychiatry. Oxford University Press.

12. Drucker, P.F. (1968). The Age of Discontinuity. New York: Harper \& Row.

13. Galbraith, J.K. (1977). The Age of Uncertainty. Boston: Houghton Mifflin.

14. Albrecht, K. (1979). Stress \& the Manager. Englewood Cliffs, N.J: Prentice-Hall.

15. Lazarus, R.S. (1966). Psychological Stress and the Coping Process. New York: McGraw Hill.

16. Cooper, C, Copper, R., \& Eaker, L. (1988). Living with stress. London: Penguin - An excellent comprehensive summary of stress and Low to manage in particularly good at comparing different occupational and cultural groups.

17. Pahl, J.M., \& Pahl, R.E. (1971). Managers and their Wives, London Allen lane.

18. Dohrenwend, B.S., \& Dohrenwend, B.P. (1975). Stressful Life Events. New York Wiley.

19. Packard, V. (1975). A nation of strangers, New York Mckay.

20. Lucas, H. (1975). Why information systems fail. New York: Columbia University Press.

21. Margolis, B.L. \& Kroes, W.H. (1974). Occupational Stress and Strain. In A.

22. Kruger, I., \& Miller, J. (1976). Management Information Systems: Success or Failure. Atlantic Economic Review, 26 (6), 10-16.

23. Ivancevich, M. J., \& Matteson, T. M. (1993). Organizational Behavior and Management ( $3^{\text {rd }}$ ed.), Irwin, Homewood, 41, 224.

24. Capowski, S.G. (1993). "Stress and the working woman", Management Review, P. 5

25. Mason, J.W. (1975). A Historical view of stress field. Human stress, 1, 6-12.
26. Weiss, M.H., Diagen, D.W.\& Sharkangh, E.M. R.D. (1982). Effects of the life and Job stress on Information search behaviors of Organizational Members", Journal of Applied Psychology, 60-62.

27. Cooper, L.C., \& Payne, R. (1978). Stress at work, (1st ed.). John Wiley and Sons: New York.

28. Baron, A.R. (1986). Behaviour in Organization, 2nd Ed., Allyn and Bacon,

29. Parker, D.F., \& De Cotiis, T.A. (1983). Organizational Determinants of Job

30. Holmes, T.H., \& Rahe, R. H. (1967)."The Social Readjustment Rating Scale". Journal of Psychosomatic Research, 11, 213-218.

31. Naaz, N., \& Ahmad, A. (2020). Job Stress during COVID - 19 pandemic among teaching and non teaching employees working in constituent colleges of L. N. Mithila University, India. Saudi Journal of Humanities and Social Sciences, \%(8). 448 - 455.

32. Rahman, I., \& Akhtar, S.S. (1991). 'Organizational Change Scale', Department of Psychology, Aligarh Muslim University, Aligarh, India.

33. Srivastava, A.K., \& Singh, A.P. (1981).Occupational Stress Index: Manual, Department of Psychology, Banaras Hindu University, Varanasi, India.

34. Mumford, E. (1969). Implementing EDP Systems A Sociological perspective. The Computer Bulletin, January, 10-13.

35. Jones, R. A., Jimmieson, N. L. \& Griffiths, A. (2005). The impact of organizational culture and reshaping capabilities on change implementation success: The mediating role of readiness for change. Journal of Management Studies, 42, 361 386. 